\title{
Novel Study on N-Nitrosamines as Risk Factors of Cardiovascular Diseases
}

\author{
Salah A. Sheweita, ${ }^{1}$ Heba A. El-Bendery, ${ }^{1}$ and Mostafa H. Mostafa ${ }^{2}$ \\ ${ }^{1}$ Department of Biotechnology, Institute of Graduate Studies \& Research, Alexandria University, 163 Horreya Avenue, \\ P.O. Box 832, EL-Chatby, Alexandria 21526, Egypt \\ ${ }^{2}$ Department of Environmental Studies, Institute of Graduate Studies \& Research, Alexandria University, \\ 163 Horreya Avenue, P.O. Box 832, EL-Chatby, Alexandria 21526, Egypt
}

Correspondence should be addressed to Salah A. Sheweita; ssheweita@yahoo.com

Received 6 June 2014; Accepted 28 July 2014; Published 27 August 2014

Academic Editor: Abel Romero-Corral

Copyright (C) 2014 Salah A. Sheweita et al. This is an open access article distributed under the Creative Commons Attribution License, which permits unrestricted use, distribution, and reproduction in any medium, provided the original work is properly cited.

Millions of people are exposed daily to N-nitrosamines from different environmental sources. The present study aims at investigating the role of $\mathrm{N}$-nitrosamines in the alteration of homocysteine, lipid profile, oxidative stress, paraoxonase activity, antioxidant enzymes, and free radicals which are important risk factors for CVD. In addition, biomarkers of cardiovascular diseases such as creatine kinase $\mathrm{MB}$ activity $(\mathrm{CK}-\mathrm{MB})$ and lactate dehydrogenase (LDH) as well as protein expression of both glutathione peroxidase and glutathione S-transferase $\pi$ isozyme were assayed after treatment of rats with $0.2 \mathrm{mg} / \mathrm{kg}$ body weight of $\mathrm{N}$-nitrosodibutylamine (NDBA), N-nitrosoethylbutylamine (NEBA), N-nitrosobutylpropylamine (NBPA), N-nitrosodiethylamine (NDEA), N-nitrosodimethylamine (NDMA), and N-nitrosodiphenylamine (NDPA) as a daily dose for two weeks. LDL levels, paraoxonase activity, reduced glutathione levels, and glutathione reductase activities were increased, whereas HDL levels decreased after treatment of rats with most of $\mathrm{N}$-nitrosamines compared to control group. Moreover, levels of free radicals and catalase activity increased, whereas protein expression of both glutathione peroxidase and glutathione S-transferase decreased after treatment of rats with some $\mathrm{N}$-nitrosamines. The data showed that most $\mathrm{N}$-nitrosamines increased CK-MB and LDH activities. It is concluded that $\mathrm{N}$-nitrosamines increased levels of free radicals, and decreased the activity of antioxidant enzymes which may consequently increase the incidence of CVDs.

\section{Introduction}

$\mathrm{N}$-Nitrosamines are mutagenic and carcinogenic chemicals and are present in large quantities in tobacco smokes [1], pacifiers and baby bottle nipples [2], and cured meats and smoked fish [3]. In addition, N-nitrosamines can be formed endogenously from interaction of nitrate, nitrite with secondary or tertiary amines and amides in human stomach [4]. Moreover, a variety of over-the-counter drugs, food additives, cosmetics, and many agricultural chemicals have been identified as having secondary or tertiary amine or amide groups in their structure that can react with nitrite to form nitrosamines and nitrosamides from simulated human gastric conditions [5-10]. Furthermore, nitrosation of drugs with tertiary amines or amides resulted in the production of known carcinogens [11]. Recently, it has been found that prenatal exposure to nitrosatable drugs may be associated with several congenital malformations, especially with higher nitrite intake [12]. Various N-nitrosamines have been observed to cause abnormal development through DNA alkylation of target organs [13]. A frog embryo exposed to $\mathrm{N}$-nitrosamines was found to develop severe heart defects [14]. In rats, maternal exposure to such compounds resulted in increased incidence of limb malformations, neural tube defects, microcephalus, and hydrocephalus $[15,16]$.

Prevalence of coronary artery atherosclerosis is increasing worldwide on an annual basis and is the leading cause of millions of deaths in the Western world. The number of people who die from CVDs will increase to reach 23.3 million by $2030[17,18]$. Hypercholesterolemia, hypertension, 
smoking, diabetes, and oxidative stress have been identified as risk factors for atherosclerosis development [18]. In addition, many genetic factors are involved in the development of CVDs [19]. Although the outstanding pathological feature of atherosclerosis is the collection of cholesterol esters from circulating lipoproteins in the intimal layer of large arteries, it remains relatively poor predictor of CVDs. Oxidized LDL [LDLoxid] has been reported to be a trigger of atherogenic events which induce proinflammatory molecules that lead to an increase in recruitment of inflammatory cells to the artery wall [20]. HDL, on the other hand, is antiatherogenic, and its protective effects have been ascribed primarily to its ability to shuttle excess cholesterol from peripheral tissues $[21,22]$. These protective effects of HDL have been attributed to the presence of various proteins associated with HDL in the circulation including apolipoprotein AI, lecithin cholesterylacyltransferase [LCAT], and serum paraoxonases (PONs) [19]. Paraoxonase is synthesized in the liver and in serum is almost exclusively associated with HDL. The enzyme paraoxonase-1 (PON-1) contributes to the antiatherogenic effects of HDL. The antiatherogenic potential of paraoxonase is derived from its capacity to hydrolyze oxidized lipids, phospholipids, cholesterol ester, and hydroperoxides, thus preventing them from accumulating in LDL particles [23].

Several pathophysiological mechanisms involved in the development of atherosclerosis are well known [19]. One of these mechanisms, it has been found that reactive oxygen species or free radical-induced oxidation of lipoproteins may be an important event in this process [19]. Human exposure to different sources of reactive oxygen species [ROS] leads to oxidative stress. Oxidative stress can be generated from secretions by phagocytic white blood cells, dysfunctional endothelial cells or from the autooxidation of catecholamines as the extracellular sources of ROS, while impaired mitochondrial reduction of molecular oxygen is the intracellular source of ROS [24]. In addition, ROS may also result from cellular injury due to exposure to ionizing radiation, ultraviolet rays, cigarette smoking, or other air pollutants and toxic chemicals $[25,26]$. Oxidative stress plays an important role in the progression of a number of diseases including atherosclerosis, ischemia-reperfusion injury, hypertension, catecholamineinduced cardiomyopathy, hypertrophy, and congestive heart failure [27]. Excessive production and/or inadequate removal of reactive oxygen species, especially superoxide anion $\left(\mathrm{O}_{2}{ }^{--}\right)$, have been implicated in the pathogenesis of many cardiovascular diseases by decreasing nitric oxide (NO) bioactivity [28]. Antioxidant enzymes as superoxide dismutase (SOD), catalase, glutathione peroxidase, glutathione reductase, and glutathione S-transferase and nonenzymatic antioxidants as glutathione, vitamin $\mathrm{C}$, and vitamin $\mathrm{E}$ have been involved in scavenging of free radicals from different tissues [29, 30].

No previous studies have been conducted on the role of $\mathrm{N}$-nitrosamines as risk factors for the incidence of cardiovascular disease since these compounds are present in many different environmental sources. Therefore, the present study was planned to investigate their effects on the different biochemical parameters as lipid profiles, paraoxonase, homocysteine levels, glutathione levels, free radicals, glutathione
S-transferase, glutathione peroxidase, and catalase activities as well as other cardiovascular biomarkers such as creatine kinase $\mathrm{MB}$ and lactate dehydrogenase in plasma and livers of male rats.

\section{Materials and Methods}

2.1. Chemicals. Diethylnitrosamine, dibutylnitrosamine, ethylbutylnitrosamine, propylbutylnitrosamine, diphenylnitrosamine, dimethylnitrosamine, sodium dithionite, nicotinamide adenine dinucleotide phosphate reduced (NADPH) sodium salt, sulfosalicylic acid, bis-(3-carboxy-4-nitrophenyl)-disulfide, 1-chloro-2,4-dinitrobenzene, and all other chemicals were purchased from Sigma Chemical Co., St. Louis, MO, USA.

2.2. Animals. Seventy male Sprague-Dawley rats weighing 200-220 g were obtained from the animal house of the Faculty of Medicine, Alexandria University, Alexandria, Egypt. Rats were housed in standard cages and given food and water. The animals were divided into seven groups. The first group (10 rats) was kept as control and received distilled water. The other six groups (10 rats each) were given $0.2 \mathrm{mg} / \mathrm{kg}$ as a daily dose of $\mathrm{N}$-nitrosodibutylamine, $\mathrm{N}$-nitrosoethylbutylamine, $\mathrm{N}$-nitrosobutylpropylamine, $\mathrm{N}$ nitrosodiethylamine, $\mathrm{N}$-nitrosodimethylamine, and $\mathrm{N}$-nitrosodiphenylamine for two weeks. At the end of the experimental period, rats were sacrificed by cervical decapitation after administration of diethyl ether as anesthetic, and fasting blood samples were collected in heparinized tubes. Plasma samples were obtained by centrifugation at $4000 \mathrm{rpm}$ for $20 \mathrm{~min}$ and stored at $-80^{\circ} \mathrm{C}$ until use.

2.3. Enzyme Assessments. At the designated time point, rats were anesthetized with ether and the thoracic cavity was opened for whole body. Liver tissues were vigorously washed in an iced solution of $0.25 \mathrm{M}$ sucrose, which contained $0.001 \mathrm{M}$ EDTA, to avoid contamination from erythrocytecontaining enzymes. Liver tissues were homogenized in 3 volumes of $0.1 \mathrm{M}$ phosphate buffer ( $\mathrm{pH} 7.4$ ) and centrifuged at $12000 \times \mathrm{g}$ for $20 \mathrm{~min}$ at $4^{\circ} \mathrm{C}$. Reduced glutathione level was estimated in homogenate supernatant of liver tissue using sulfosalicylic acid for protein precipitation and bis(3-carboxy-4-nitrophenyl)-disulfide for color development, Mitchell et al., 1973 [31]. Glutathione reductase activity was assayed in the supernatant of liver tissue homogenate by monitoring the oxidation of NADPH at $340 \mathrm{~nm}$ using the method of Suojanen et al., 1980 [32]. A unit of enzyme activity represents $1 \mathrm{nmol}$ of NADPH oxidized/min per $\mathrm{mg}$ protein. GST activity was determined according to the method of Lee et al., 1981 [33]. The conjugate of GSH with 1-chloro2,4-dinitrobenzene (CDNB) was measured at $340 \mathrm{~nm}$ using a double beam spectrophotometer. A unit of enzyme activity is defined as the amount of enzyme that catalyzes the formation of $1 \mathrm{mmol}$ of CDNB conjugate/mg protein/min under the assay conditions. Calculations were made using a molar extinction coefficient of $9.6 \mathrm{mM}^{-1} \mathrm{~cm}^{-1}$. The protein 
concentration was measured by the method of Lowry et al. [34] using bovine serum albumin as standard.

Thiobarbituric acid-reactive substances (TBARS) were measured in the supernatant of liver tissue homogenates as described by Tappel and Zalkin, 1959 [35]. The color intensity of the TBARS reactants as malondialdehyde was measured at $532 \mathrm{~nm}$ and a molar extinction coefficient of $156,000 \mathrm{M}^{-1} \mathrm{~cm}^{-1}$ was used for calculation of the TBARS concentration.

2.3.1. Total Cholesterol Level. Cholesterol was determined enzymatically with cholesterol esterase and cholesterol oxidase. Cholesterol esters are cleaved by the action of cholesterol esterase to yield free cholesterol and free fatty acids. The color intensity is directly proportional to the concentration of cholesterol and was determined spectrophotometrically. The full procedure of cholesterol determination was followed according to the instructions of the kit provided by Biosystems, Barcelona, Spain.

2.3.2. Lipid Determinations. Briefly, HDL was measured in the plasma after precipitation of apolipoprotein B-containing particles with dextran sulfate- $\mathrm{MgCl}_{2}$. For LDL, a specific detergent solubilizes the cholesterol from HDL, very lowdensity lipoproteins and chylomicrons. The cholesterol esters are broken down by cholesterol esterase and cholesterol oxidase in a non-color-forming reaction. The second detergent (MES buffer, $>30 \mathrm{mmol} / \mathrm{l}, \mathrm{N}, \mathrm{N}$-bis(4-sulfobutyl)-m-toluidine $1 \mathrm{mmol} / \mathrm{l}$, detergent, $\mathrm{pH}$ 6.3) solubilizes cholesterol from LDL in the sample, and LDL-cholesterol is then measured spectrophotometrically at $546 \mathrm{~nm}$. The full procedure of HDLand LDL-cholesterol determination was followed according to the instructions of kits provided by Biosystems, Barcelona, Spain.

2.3.3. Homocysteine Determination. Most homocysteine in plasma is bound to proteins by disulfide bonds with thiolcontaining residues; oxidized homocysteine and homocysteine-cysteine mixed disulfide are also present. Total homocysteine was measured after reduction of disulfide bonds and detection of released homocysteine by use of dithiothreitol. Homocysteine in test samples is converted to S-adenosyl-L-homocysteine (SAH) by use of S-adenosyl-Lhomocysteine hydroxylase and excess adenosine. The subsequent solid-phase enzyme immunoassay is based on competition between $\mathrm{SAH}$ in the sample and immobilized $\mathrm{SAH}$ bound to the walls of the microtiter plate for binding sites on a monoclonal anti-SAH antibody. After removal of antiSAH antibody not bound to the plate, a secondary rabbit anti-mouse antibody labeled with horseradish peroxidase is added. Peroxidase activity is measured spectrophotometrically after addition of the substrate, and the absorbance is inversely related to the concentration of total homocysteine in the sample [36]. The full procedure for homocysteine determination was followed according to the instructions for the homocysteine enzyme immunoassay kit (Axis-Shield, Germany).
2.3.4. Superoxide Dismutase Assay. SOD was measured according to the method of Beers and Sizer, 1952 [37]. SOD estimation is based on the generation of superoxide radicals produced by xanthine and xanthine oxidase, which react with nitroblue tetrazolium to form formazin dye. SOD activity is then measured at $560 \mathrm{~nm}$ by the degree of inhibition of this reaction and expressed as $\mathrm{mmol} / \mathrm{min} / \mathrm{mL}$ of plasma.

2.3.5. Glutathione Peroxidase. Glutathione peroxidase enzyme activity (GPx; EC. 1.11.1.9) was assayed according to the method of Chiu et al., 1976 [38]. The reaction mixture $(1 \mathrm{~mL})$ containing $0.05 \mathrm{~mL}$ of the enzyme source, $0.05 \mathrm{M}$ Tris$\mathrm{HCl}$ buffer ( $\mathrm{pH}$ 7.6), $1.5 \mathrm{mM} \mathrm{GSH}$, and cumenehydroperoxide was incubated for $5 \mathrm{~min}$ at $37^{\circ} \mathrm{C}$. In another tube, the control sample was prepared without cumenehydroperoxides and incubated for $5 \mathrm{~min}$ at $37^{\circ} \mathrm{C}$. To both control and test samples, $1.0 \mathrm{~mL}$ of TCA (15\%) was added, while $0.1 \mathrm{~mL}$ cumenehydroperoxide was added to the control only. Both tubes were incubated for $10 \mathrm{~min}$ at $37^{\circ} \mathrm{C}$ and centrifuged at $3000 \mathrm{rpm}$ for 20 min. Tris-HCL buffer ( $\mathrm{pH} 8.9$ ) and $1.5 \mathrm{mM}$ DTNB were added to $1 \mathrm{~mL}$ supernatant for both sample and control. The optical density of the yellow color obtained was measured at $412 \mathrm{~nm}$ within $5 \mathrm{~min}$. Result was expressed as U/gm tissue.

2.3.6. Catalase Activity. Catalase activity was determined by the method by Beers and Sizer, 1952 [37], which is based on decreasing absorbance of $\mathrm{H}_{2} \mathrm{O}_{2}$ solution decomposed by the enzyme, with a kit obtained from Randox Laboratory, UK. The quantity of $\mathrm{H}_{2} \mathrm{O}_{2}$ decomposed over a specified time is calculated from the molar absorbance coefficient. Absorbance is measured at $240 \mathrm{~nm}$ and catalase activity is expressed as IU/gm tissue.

2.3.7. Creatine Kinase $M B$. A specific antibody inhibits the $\mathrm{M}$ subunits of $\mathrm{CK} \mathrm{MM}$ and $\mathrm{CK} \mathrm{MB}$ and thus allows determination of the $\mathrm{B}$ subunit of $\mathrm{CK} \mathrm{MB}$ (assuming absence of $\mathrm{CK} \mathrm{BB}$ and $\mathrm{CK}$ 1); $\mathrm{Ck} \mathrm{B}$ catalytic concentration which responds to half of $\mathrm{CK} \mathrm{MB}$ concentration is determined by rate of NADPH formation, measured at $340 \mathrm{~nm}$ by means of hexokinase and glucose 6 phosphate dehydrogenase coupled reactions. The full procedure of creatine kinase MB determination was followed according to the instructions with the kit (spectrum diagnostics, Hannover, Germany).

2.3.8. Lactate Dehydrogenase Determination. Lactate dehydrogenase $\mathrm{LDH}$ catalyzes the reduction of pyruvate by NADH to form lactate and NAD+. The catalytic concentration is determined from the rate of decrease of NADH measured at $340 \mathrm{~nm}$. The full procedure of lactate dehydrogenase determination was followed according to the instructions of the kit (Biosystems, Barcelona, Spain).

2.3.9. Paraoxonase Activity. Paraoxonase activity was measured according to method of Eckerson et al., 1983 [39], with $1 \mathrm{mM}$ paraoxon in total volume of $800 \mu \mathrm{L}$. Enzyme activity was measured in $50 \mathrm{mM}$ Tris-HCL buffer. Nonenzymatic assay mixture contained $600 \mu \mathrm{L}$ buffer and $200 \mu \mathrm{L}$ 
paraoxon as substrate, while enzymatic assay mixture contained enzyme to start the reaction. The amount of formed pnitrophenol was measured spectrophotometrically at $412 \mathrm{~nm}$. The enzymatic activity was calculated using $12,800 \mathrm{M}^{-1} \mathrm{Cm}^{-1}$ as molar extinction coefficient. Blank contained substrate without enzyme, one unit of paraoxonase activity defined as 1 nmole of 4-nitrophenol formed per min under the above conditions [23].

2.3.10. Western Immunoblotting. From pooled sample of each treatment, $20 \mu \mathrm{g}$ of S-9 liver supernatant proteins was prepared and subjected to SDS-polyacrylamide gel electrophoresis. Proteins were transblotted to Hybond-C nitrocellulose membrane (Amersham, UK). GST $\pi$ isozyme and glutathione peroxidase were visualized after binding with their specific monoclonal antibodies. Chemiluminescence signals of both were detected according to the manufacturer's instructions (Abcam, UK) [40].

2.4. Statistical Analysis. Means and standard errors were calculated. Data were analyzed by one-way analysis of variance (ANOVA) compared with Student's $t$-test. The level of significance for all experiments was set at $P<0.05$.

\section{Results}

The present study showed that the level of cholesterol increased by 13,20 , and $16 \%$ after treatment of male rats for two weeks as repeated doses with diethyl-, dimethyl-, and diphenylnitrosamine, respectively, while other compounds have no significant effects compared to control group (Table 1). On the other hand, the level of HDL decreased by $24,27,32,31$, and $33 \%$ and LDL level increased by 18, 44, 20, 29 , and $27 \%$ and paraoxonase activity increased by $84,40,81$, 121 , and $48 \%$ in plasma of rats after treatment with ethylbutyl, butylpropyl-, diethyl-, dimethyl-, and diphenylnitrosamine, respectively, compared to control group (Table 1).

Biomarkers of cardiovascular diseases, creatine kinase MB activity, increased by $86,71,91,100$, and $103 \%$ after rat treatment with dibutyl-, ethylbutyl-, butylpropyl-, diethyl-, and dimethylnitrosamine whereas diphenylnitrosamine has no significant effect compared to control group (Table 1). In addition, the activity of lactate dehydrogenase increased by 44 and $50 \%$ after treatment with dibutyl- and diethylnitrosamine while the other nitrosamines have no significant effects compared to control group (Table 1). Homocysteine level is increased in rat plasma by $25 \%$ after treatment with dibutylnitrosamine and decreased by 19 and $25 \%$ after treatment with ethylbutyl- and dimethylnitrosamine, respectively, while the other nitrosamines have no significant effect compared to control group (Table 1). Treatment of rats with dibutyl-, ethylbutyl-, butylpropyl-, diethyl-, and dimethylnitrosamine increased both reduced GSH level and GR activity by $25,20,23,22$, and $39 \%$ and $100,44,34$, 55 , and $54 \%$, respectively (Table 2 ). Glutathione peroxidase activity decreased by $69,71,70,57,43$, and $15 \%$ after treatment of rats with dibutyl-, ethylbutyl-, butylpropyl-, diethyl-, dimethyl-, and diphenylnitrosamine, respectively (Table 2),

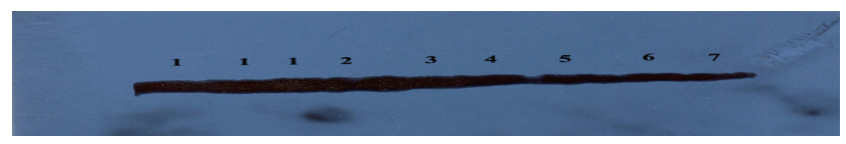

FIGURE 1: Western immunoblot analysis showed the protein expression of glutathione peroxidase. Lanes $1,2,3,4,5,6$, and 7 represent the pooled proteins of matched control, diphenylnitrosamine, dimethylnitrosamine, diethylnitrosamine, butylpropylnitrosamine, ethylbutylnitrosamine, and dibutylnitrosamine-treated groups, respectively.

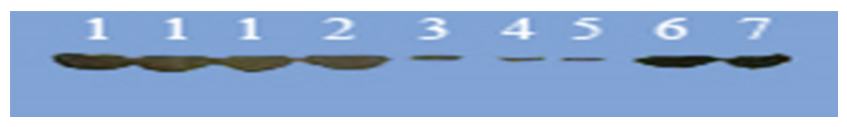

FIGURE 2: Western immunoblot analysis showed the protein expression of glutathione S-transferase $\pi$ isozyme. Lanes $1,2,3,4,5,6$, and 7 represent the pooled proteins of matched control, diphenylnitrosamine, dimethylnitrosamine, diethylnitrosamine, butylpropylnitrosamine, ethylbutylnitrosamine, and dibutylnitrosaminetreated groups, respectively.

whereas treatment of rats with dibutyl-, ethylbutyl-, and dimethylnitrosamine increased catalase activity by 131, 169, and $342 \%$, respectively (Table 2 ). In addition, the protein expression of glutathione peroxidase was also reduced after treatment of rats with diethylnitrosamine, butylpropylnitrosamine, ethylbutylnitrosamine, and dibutylnitrosamine for the same period (Figure 1).

The activity of total GST increased by 54,60 , and $51 \%$ after treatment of rats with dibutyl-, ethylbutyl-, and diethylnitrosamine, respectively, and decreased by $36 \%$ after treatment with diphenylnitrosamine (Table 2). The western immunoblotting of glutathione S-transferase pi isozymes was markedly inhibited after treatment of rats with diethylnitrosamine, butylpropylnitrosamine, ethylbutylnitrosamine, and dibutylnitrosamine for two weeks (Figure 2). The levels of malondialdehyde, indicator of free radical, increased by $98,52,45$, and $131 \%$ after treatment with dibutyl-, ethylbutyl-, butylpropyl-, and dimethylnitrosamine, respectively (Table 2). On the other hand, SOD activity decreased by 48,52 , and $52 \%$ by dibutyl-, butylpropyl-, and diphenylnitrosamine, respectively, compared to control (Table 2).

\section{Discussion}

Hypercholesterolemia (HC), especially high levels of lowdensity lipoprotein-cholesterol (LDL), is an important risk factor accounting for severe atherosclerotic diseases [41]. When LDL enters into the endothelium of vessel walls by a concentration-dependent mechanism, reactive oxygen species (ROS) exert oxidative attack on lipid and protein components of LDL generating oxidized LDL (LDLox) [42, 43]. Additionally, LDLox can initiate and enhance the inflammatory process, which plays a vital role in the development of atherosclerotic changes [44]. In accordance with 


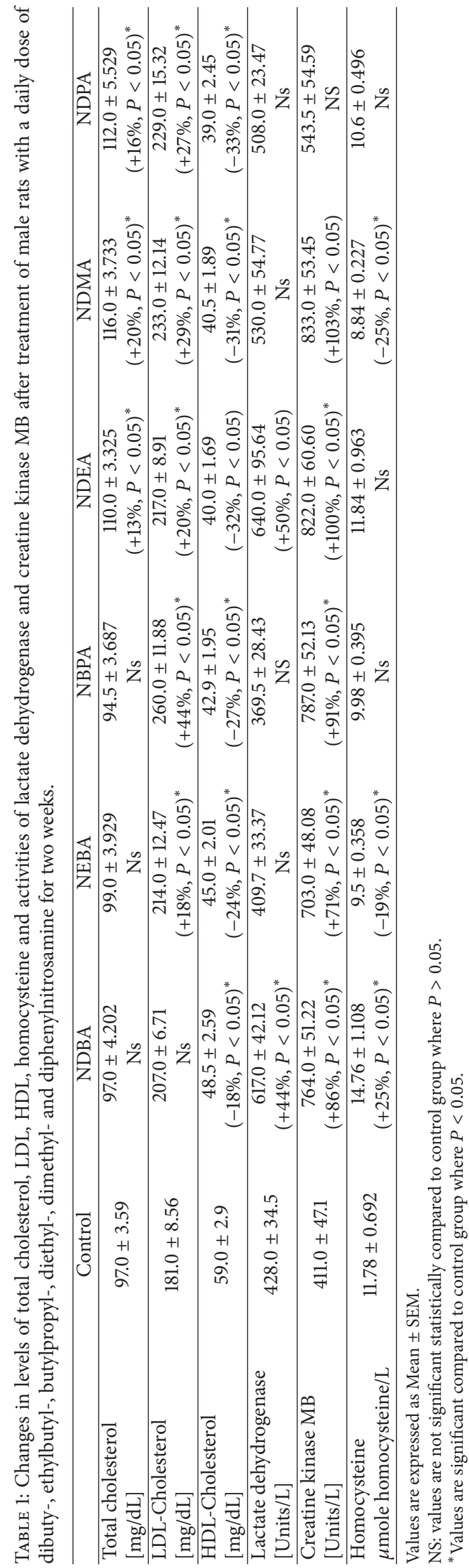




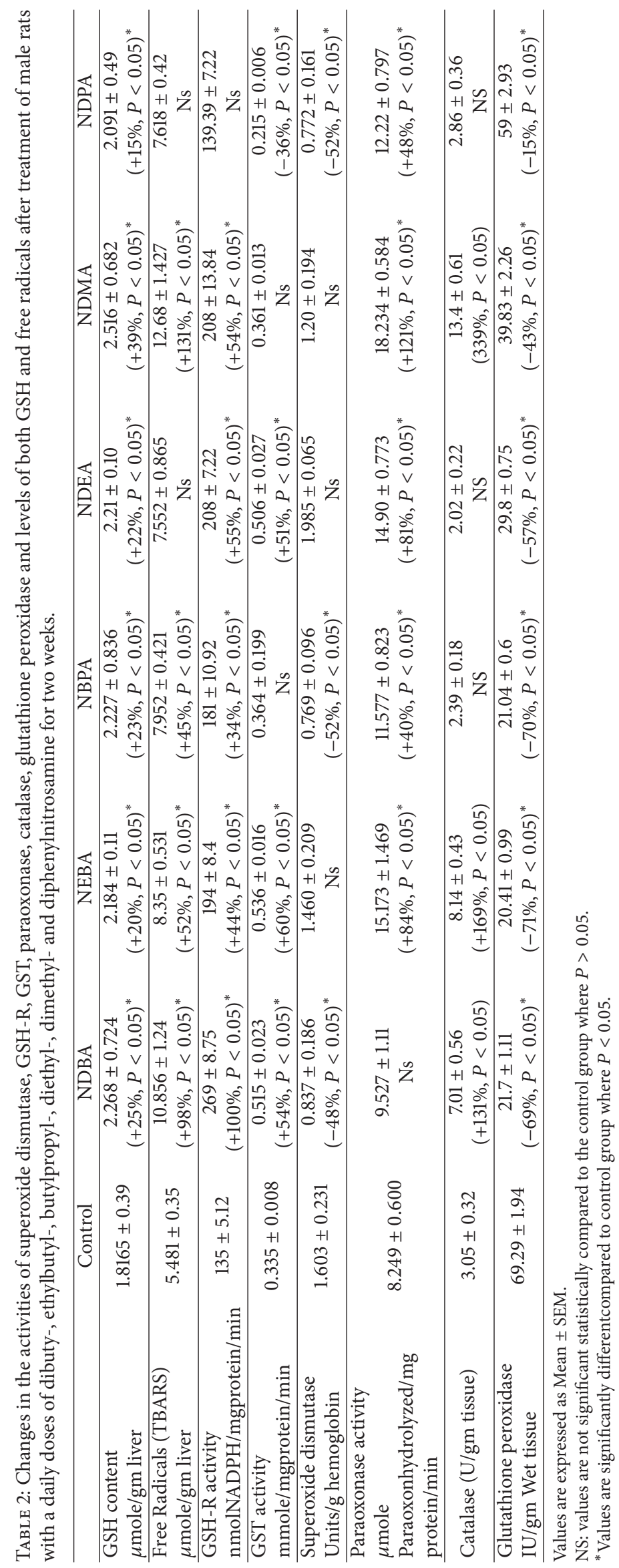


these findings, the present study showed that LDL levels have been increased after treatment of rats with all tested $\mathrm{N}$-nitrosamines except NDBA did not change such level (Table 1). It is well known that conversion of HDL into LDL is mediated via different mechanisms, and free radicals are involved in such conversion $[42,43]$. In agreement with these findings, levels of both generated free radicals and LDL were markedly increased, whereas HDL levels decreased after treatment of rats with different types of $\mathrm{N}$-nitrosamines (Table 1). It is thought that paraoxonase enzyme protects HDL against oxidation which mediated via reactive oxygen species $[19,45]$. However, in the present study, paraoxonase could not protect HDL from oxidation since its activity was potentially induced and HDL levels decreased after treatment of rats with various types of $\mathrm{N}$-nitrosamines (Table 1 ). This discrepancy might be due to the presence of more than one type of paraoxonase isozyme [19]. In the present study, the total activities of all types of paraoxonase were measured but not the specific activity of paraoxonase- 1 which is associated with HDL.

It is well known that high levels of free radicals lead to oxidative stress, which is involved in the initiation and progression of different types of cardiovascular diseases [19, 46 , 47]. Supporting our finding, CVD biomarker, CK-MB activity, has been markedly increased in the plasma of $\mathrm{N}$ nitrosamines-treated rats (Table 1). From the present study, $\mathrm{LDH}$ enzyme is not specific biomarker for CVD since its activity did not change in plasma of treated rats except NDBA and NDEA increased such activity (Table 1). Therefore, this study could provide a new possible reason for the incidence of CVDs among people who are exposed to these compounds from different environmental sources as tobacco smoke and cured foods.

It is well known that increasing level of homocysteine is a risk factor for cardiovascular disease and plays a significant role in the incidence of CVD [48] via different mechanisms including endothelial dysfunction, superoxide and hydrogen peroxide generation, and promoted proliferation of the aortic smooth muscle cells. However, in the present study, the level of homocysteine did not change after treatment of rats with most of N-nitrosamines except NEBA and NDMA decreased such level (Table 1). Therefore, it is suggested that $\mathrm{N}$-nitrosamines could induce the incidence of CVDs via a mechanism other than increasing of homocysteine levels which might be due to generation of high levels of ROS which are linked to the damage of endothelial lining of arterial vessels $[46,47,49]$. ROS induce specific posttranslational modifications that alter the function of important cellular proteins and signaling pathways in the heart [50-54].

It is well known that antioxidant enzymes such as superoxide dismutase, glutathione peroxidase, glutathione reductase, and catalase play a significant role in the removal of free radicals such as active superoxide and hydroxy radicals from different tissues. Therefore, in the present study, increasing free radical levels after treatment of rats with different $\mathrm{N}$-nitrosamines is mainly due to inhibition of antioxidant enzymes such as superoxide dismutase and glutathione peroxidase (Table 2). In addition, protein expression of glutathione peroxidase decreased after treatment of rats with most of N-nitrosamines (Table 2 and Figure 1). Activity of antioxidant enzymes such as catalase, glutathione peroxidase-1 (GPX-1), and SOD has been quantified in plasma as measures of antioxidant capabilities. In a prospective study of patients with suspected coronary artery disease, erythrocyte GPX-1 and SOD activity were inversely associated with incidence of cardiovascular events after adjusting risk factors of cardiovascular diseases $[55,56]$.

The glutathione (GSH) and GSH S-transferases system are major players in protection against a broad variety of toxic agents involved in the pathogenesis of several chronic degenerative diseases [57-60]. The present study provides further evidence to these findings since the protein expression of GST $\pi$ was potentially reduced after treatment of rats with dimethylnitrosamine, diethylnitrosamine, butylpropylnitrosamine, ethylbutylnitrosamine, and dibutylnitrosamine (Figure 2). It seems from this study that the chemical structure of these compounds plays a significant role in the modification of GST expression since the substitution of the diphenyl by diethyl, ethylbutyl, and/or dibutyl on the nitroso group changed the activity and the expression of GST. The inhibition of GST activity could potentiate the toxicity of environmental carcinogens and might increase the probability of DNA binding with the ultimate metabolites of well-known carcinogens. Supporting our finding, it has been found that DNA adducts of GSTM1 gene in smooth muscle cells (SMC) of human abdominal and thoracic aortic samples were higher in subjects with frequent atherosclerotic changes as compared to subjects with rare lesions [61, 62]. In addition, the level of GSH was increased after treatment of rats with all tested $\mathrm{N}$-nitrosamines (Table 2). It is taught that increment in GSH might be due to induction of GSH synthase and gamma-glutamyltransferase [63-65]. However, in the present study, the increased level of GSH was found to be dependent on the activity of GR since the activity of GR was also potentially induced after treatment of rats with $\mathrm{N}$ nitrosamines (Table 2). These increments in both GSH levels and GR activity might be a defense mechanism of the treated animals to reduce the toxicity of N-nitrosamines [66].

It is concluded that $\mathrm{N}$-nitrosamines could induce CVDs via increasing free radical, LDL levels and inhibition of antioxidant enzyme activities as well as decreasing HDL levels. In addition, the protein expressions of both GST $\pi$ and glutathione peroxidase were decreased after exposure to these compounds. CVDs biomarker, CK-MB activity, was also potentially induced, and these changes might explain the implication of these compounds in the initiation and progression of CVD. Also, this study might provide an explanation for the association of tobacco smokers with CVDs since tobacco is a major risk factor for cardiovascular disease due to the presence of these compounds in large quantities [67].

\section{Conflict of Interests}

The authors declare that there is no conflict of interests regarding the publication of this paper. 


\section{Acknowledgment}

Authors are grateful to STDF, Cairo, Egypt, for its financial support of the proposal of M.S. thesis of Heba A. El-Bendery, Department of Biotechnology, IGSR, Alexandria University, Egypt.

\section{References}

[1] D. L. Ashley, R. J. O’Connor, J. T. Bernert et al., "Effect of differing levels of tobacco-specific nitrosamines in cigarette smoke on the levels of biomarkers in smokers," Cancer Epidemiology Biomarkers and Prevention, vol. 19, no. 6, pp. 1389-1398, 2010.

[2] R. Clapp, M. Jacobs, and W. Lijinsky, "N-nitroso compounds," in Patty's Toxicology, pp. 401-432, Wiley, 2012.

[3] W. Lijinsky, "N-nitroso compounds in the diet," Mutation Research-Genetic Toxicology and Environmental Mutagenesis, vol. 443, no. 1-2, pp. 129-138, 1999.

[4] A. R. Tricker, "N-nitroso compounds and man: sources of exposure, endogenous formation and occurrence in body fluids," European Journal of Cancer Prevention, vol. 6, no. 3, pp. 226268, 1997.

[5] D. Ziebarth and B. Teichmann, "Nitrosation of orally administered drugs under simulated stomach conditions," IARC Scientific Publication, no. 31, pp. 231-244, 1980.

[6] R. Preussmann, "Occurrence and exposure to N-nitroso compounds and precursors," IARC scientific publications, no. 57, pp. 3-15, 1984.

[7] A. Sakai, T. Inoue, and A. Tanimura, "Formation of volatile nitrosamines by drug-nitrite interactions under physiological conditions," Gann, vol. 75, no. 3, pp. 245-252, 1984.

[8] P. N. Gillatt, R. C. Palmer, P. L. Smith, C. L. Walters, and P. I. Reed, "Susceptibilities of drugs to nitrosation under simulated gastric conditions," Food and Chemical Toxicology, vol. 23, no. 9, pp. 849-855, 1985.

[9] T. Ohta, Y. Asabe, and S. Takitani, "Identification of mutagenic nitrosation products of antipyrine and evaluation of their formation under model stomach conditions," Chemical and Pharmaceutical Bulletin, vol. 34, no. 9, pp. 3866-3872, 1986.

[10] D. Ziebarth, T. Schramm, and A. Toppel, "Drugs from the classes of tricyclic antidepressives and antiepileptics, nitrosatable under simulated human gastric conditions," Archiv fur Geschwulstforschung, vol. 59, no. 4, pp. 257-263, 1989.

[11] G. Brambilla and A. Martelli, "Genotoxic and carcinogenic risk to humans of drug-nitrite interaction products," Mutation Research-Reviews in Mutation Research, vol. 635, no. 1, pp. 1752, 2007.

[12] J. D. Brender, M. M. Werler, M. U. Shinde et al., "Nitrosatable drug exposure during the first trimester of pregnancy and selected congenital malformations," Birth Defects Research A, vol. 94, no. 9, pp. 701-713, 2012.

[13] G. Bochert, T. Platzek, G. Blankenburg, M. Wiessler, and D. Neubert, "Embryotoxicity induced by alkylating agents: left-sided preponderance of paw malformations induced by acetoxymethyl-methylnitrosamine in mice," Archives of Toxicology, vol. 56, no. 3, pp. 139-150, 1985.

[14] D. J. Fort, J. R. Rayburn, D. J. DeYoung, and J. A. Bantle, "Assessing the efficacy of an Aroclor 1254-induced exogenous metabolic activation system for FETAX," Drug and Chemical Toxicology, vol. 14, no. 1-2, pp. 143-160, 1991.
[15] T. Koyama, J. Handa, H. Handa, and S. Matsumoto, "Methylnitrosourea-induced malformations of brain in SD-JCL rat.", Archives of Neurology, vol. 22, no. 4, pp. 342-347, 1970.

[16] S. A. Sheweita and B. Y. Sheikh, "Can dietary antioxidants reduce the incidence of brain tumors?" Current Drug Metabolism, vol. 12, no. 6, pp. 587-593, 2011.

[17] C. D. Mathers and D. Loncar, "Projections of global mortality and burden of disease from 2002 to 2030," PLoS Medicine, vol. 3, no. 11, pp. 2011-2030, 2006.

[18] D. Mozaffarian, P. W. F. Wilson, and W. B. Kannel, "Beyond established and novel risk factors lifestyle risk factors for cardiovascular disease," Circulation, vol. 117, no. 23, pp. 30313038, 2008.

[19] S. A. Sheweita, H. Baghdadi, and A. R. Allam, "Role of genetic changes in the progression of cardiovascular diseases," International Journal of Biomedical Science, vol. 7, no. 4, pp. 238-248, 2011.

[20] H. Soran, N. N. Younis, V. Charlton-Menys, and P. Durrington, "Variation in paraoxonase-1 activity and atherosclerosis," Current Opinion in Lipidology, vol. 20, no. 4, pp. 265-274, 2009.

[21] S. Deakin, I. Leviev, M. Gomaraschi, L. Calabresi, G. Franceschini, and R. W. James, "Enzymatically active paraoxonase-1 is located at the external membrane of producing cells and released by a high affinity, saturable, desorption mechanism," The Journal of Biological Chemistry, vol. 277, no. 6, pp. 43014308, 2002.

[22] L. Précourt, D. Amre, M. Denis et al., "The three-gene paraoxonase family: physiologic roles, actions and regulation," Atherosclerosis, vol. 214, no. 1, pp. 20-36, 2011.

[23] K. N. Gan, A. Smolen, H. W. Eckerson, and B. N. La Du, "Purification of human serum paraoxonase/arylesterase. Evidence for one esterase catalyzing both activities," Drug Metabolism and Disposition, vol. 19, no. 1, pp. 100-106, 1991.

[24] R. L. S. Gonçalves, J. H. M. Oliveira, G. A. Oliveira et al., "Mitochondrial reactive oxygen species modulate mosquito susceptibility to Plasmodium infection," PLOS ONE, vol. 7, no. 7, Article ID e41083, 2012.

[25] E. Pace, M. Ferraro, S. Di Vincenzo et al., "Oxidative stress and innate immunity responses in cigarette smoke stimulated nasal epithelial cells," Toxicology in Vitro, vol. 28, no. 2, pp. 292-299, 2014.

[26] C. Shen, T. W. Turney, T. J. Piva, B. N. Feltis, and P. F. Wright, "Comparison of UVA-induced ROS and sunscreen nanoparticle-generated ROS in human immune cells," Photochemistry and Photobiology Scinces, vol. 13, no. 5, pp. 781-788, 2014.

[27] T. Bahorun, A. M. Soobrattee, V. Luximon-Ramma, and O. I. Aruoma, "Free radicals and antioxidants in cardiovascular health and disease," Internet Journal of Medical Update, vol. 1, no. 2, pp. 25-41, 2006.

[28] T. Fukai and M. Ushio-Fukai, "Superoxide dismutases: role in redox signaling, vascular function and diseases," Antioxidants and Redox Signaling, vol. 15, no. 6, pp. 1583-1606, 2011.

[29] J. Mladenović, B. Ognjanović, N. Dorđević et al., "Protective effects of oestradiol against cadmium-induced changes in blood parameters and oxidative damage in rats," Arhiv za Higijenu Rada i Toksikologiju, vol. 65, no. 1, pp. 37-46, 2014.

[30] X. J. Wang, Y. Li, L. Luo et al., "Oxaliplatin activates the Keap1/Nrf2 antioxidant system conferring protection against the cytotoxicity of anticancer drugs," Free Radical Biology and Medicine, vol. 70, pp. 68-77, 2014. 
[31] J. R. Mitchell, D. J. Jollow, W. Z. Potter, D. C. Davis, J. R. Gillette, and B. B. Brodie, "Acetaminophen induced hepatic necrosis. I. Role of drug metabolism," Journal of Pharmacology and Experimental Therapeutics, vol. 187, no. 1, pp. 185-194, 1973.

[32] J. N. Suojanen, R. J. Gay, and R. Hilf, "Influence of estrogen on glutathione levels and glutathione-metabolizing enzymes in uteri and R3230AC mammary tumors of rats," Biochimica et Biophysica Acta, vol. 630, no. 4, pp. 485-496, 1980.

[33] C. Y. Lee, L. Johnson, R. H. Cox, and J. D. McKinney, "Mouse liver glutathione S-transferases. Biochemical and immunological characterization," Journal of Biological Chemistry, vol. 256, no. 15 , pp. 8110-8120, 1981.

[34] O. H. Lowry, N. J. Rosebrough, A. L. Farr, and R. J. Randall, "Protein measurement with the Folin phenol reagent," The Journal of Biological Chemistry, vol. 193, no. 1, pp. 265-275, 1951.

[35] A. L. Tappel and H. Zalkin, "Inhibition of lipide peroxidation in mitochondria by vitamin E," Archives of Biochemistry and Biophysics, vol. 80, no. 2, pp. 333-336, 1959.

[36] F. Frantzen, A. L. Faaren, I. Alfheim, and A. K. Nordhei, "Enzyme conversion immunoassay for determining total homocysteine in plasma or serum," Clinical Chemistry, vol. 44, no. 2, pp. 311-316, 1998.

[37] R. F. Beers and I. W. Sizer, "A spectrophotometric method for measuring the breakdown of hydrogen peroxide by catalase," The Journal of Biological Chemistry, vol. 195, no. 1, pp. 133-140, 1952.

[38] D. T. Y. Chiu, F. H. Stults, and A. L. Tappel, "Purification and properties of rat lung soluble glutathione peroxidase," Biochimica et Biophysica Acta (BBA)-Enzymology, vol. 445, no. 3, pp. 558-566, 1976.

[39] H. W. Eckerson, C. M. Wyte, and B. N. La Du, "The human serum paraoxonase/arylesterase polymorphism," The American Journal of Human Genetics, vol. 35, no. 6, pp. 1126-1138, 1983.

[40] P. Matsudaira, "Sequence from picomole quantities of proteins electroblotted onto polyvinylidene difluoride membranes," The Journal of Biological Chemistry, vol. 262, no. 21, pp. 10035-10038, 1987.

[41] S. Rashid, A. Sniderman, and M. Melone, "Elevated cholesteryl ester transfer protein (CETP) activity, a major determinant of the atherogenic dyslipidemia, and atherosclerotic cardiovascular disease in South Asians," European Journal of Preventive Cardiology, 2014.

[42] M. Batlouni, "Hipótese oxidativa da aterosclerose," Arquivos Brasileiros de Cardiologia, vol. 68, no. 1, pp. 55-63, 1997.

[43] M. I. Masiá, S. H. Padilla, E. Bernal et al., "Influence of antiretroviral therapy on oxidative stress and cardiovascular risk: a prospective cross-sectional study in HIV-infected patients," Clinical Therapeutics, vol. 29, no. 7, pp. 1448-1455, 2007.

[44] P. R. Augusti, A. R. Ruviaro, A. Quatrin et al., "Imbalance in superoxide dismutase/thioredoxin reductase activities in hypercholesterolemic subjects: Relationship with low density lipoprotein oxidation," Lipids in Health and Disease, vol. 11, no. 1, article 79, 2012.

[45] M. Aviram, M. Rosenblat, C. L. Bisgaier, R. S. Newton, S. L. Primo-Parmo, and B. N. La Du, "Paraoxonase inhibits highdensity lipoprotein oxidation and preserves its functions: a possible peroxidative role for paraoxonase," Journal of Clinical Investigation, vol. 101, no. 8, pp. 1581-1590, 1998.

[46] K. K. Griendling and G. A. FitzGerald, "Oxidative stress and cardiovascular injury: PartI: basic mechanisms and in vivo monitoring of ROS," Circulation, vol. 108, no. 16, pp. 1912-1916, 2003.
[47] D. Harrison, K. K. Griendling, U. Landmesser, B. Hornig, and H. Drexler, "Role of oxidative stress in atherosclerosis," The American Journal of Cardiology, vol. 91, no. 3, pp. 7A-11A, 2003.

[48] R. Pandey, S. Gupta, H. Lal, H. C. Mehta, and S. K. Aggarwal, "Hyperhomocysteinemia and cardiovascular disease: the nutritional perspectives," Indian Journal of Clinical Biochemistry, vol. 15 , no. 1, pp. 20-30, 2000.

[49] N. Inoue, "Stress and atherosclerotic cardiovascular disease," Journal of Atherosclerosis and Thrombosis, vol. 21, no. 5, pp. 391401, 2014.

[50] T. Adachi, R. M. Weisbrod, D. R. Pimentel et al., "S-glutathiolation by peroxynitrite activates SERCA during arterial relaxation by nitric oxide," Nature Medicine, vol. 10, no. 11, pp. 12001207, 2004.

[51] C. F. H. Mueller, K. Laude, J. S. McNally, and D. G. Harrison, "Redox mechanisms in blood vessels," Arteriosclerosis, Thrombosis, and Vascular Biology, vol. 25, no. 2, pp. 274-278, 2005.

[52] H. H. Rasmussen, E. J. Hamilton, C. C. Liu, and G. A. Figtree, "Reversible oxidative modification: implications for cardiovascular physiology and pathophysiology," Trends in Cardiovascular Medicine, vol. 20, no. 3, pp. 85-90, 2010.

[53] I. Dalle-Donne, G. Colombo, N. Gagliano et al., "S-Glutathiolation in life and death decisions of the cell," Free Radical Research, vol. 45, no. 1, pp. 3-15, 2011.

[54] G. A. Figtree, G. Keyvan Karimi, C. Liu, and H. H. Rasmussen, "Oxidative regulation of the $\mathrm{Na}+\mathrm{K}+$ pump in the cardiovascular system," Free Radical Biology and Medicine, vol. 53, no. 12, pp. 2263-2268, 2012.

[55] S. Blankenberg, H. J. Rupprecht, C. Bickel et al., "Glutathione peroxidase 1 activity and cardiovascular events in patients with coronary artery disease," The New England Journal of Medicine, vol. 349, no. 17, pp. 1605-1613, 2003.

[56] G. H. Kim, J. J. Ryan, and S. L. Archer, "The role of redox signaling in epigenetics and cardiovascular disease," Antioxidants and Redox Signaling, vol. 18, no. 15, pp. 1920-1936, 2013.

[57] A. Meister, "Metabolism and function of glutathione," in Glutathione: Chemical, Biochemical and Medical Aspects, D. Dolphin, R. Poulson, and O. Avramovic, Eds., pp. 361-374, John Wiley \& Sons, New York, NY, USA, 1989.

[58] S. A. Sheweita and A. K. Tilmisany, "Cancer and phase II drugmetabolizing enzymes," Current Drug Metabolism, vol. 4, no. 1, pp. 45-58, 2003.

[59] B. Ketterer, J. M. Harris, G. Talaska et al., "The human glutathione S-transferase supergene family, its polymorphism, and its effects on susceptibility to lung cancer," Environmental Health Perspectives, vol. 98, pp. 87-94, 1992.

[60] J. D. Hayes and D. J. Pulford, "The glutathione S-transferase supergene family: regulation of GST and the contribution of the isoenzymes to cancer chemoprotection and drug resistance," Critical Reviews in Biochemistry and Molecular Biology, vol. 30, no. 6, pp. 445-600, 1995.

[61] S. de Flora, A. Izzotti, D. Walsh, P. Degan, G. L. Petrilli, and J. Lewtas, "Molecular epidemiology of atherosclerosis," The FASEB Journal, vol. 11, no. 12, pp. 1021-1031, 1997.

[62] B. Binková, P. Strejc, O. Boubelík, Z. Stávková, I. Chvátalová, and R. J. Srám, "DNA adducts and human atherosclerotic lesions," International Journal of Hygene and Environmental Health, vol. 204, no. 1, pp. 49-54, 2001.

[63] O. W. Griffith, "Mechanism of action, metabolism, and toxicity of buthionine sulfoximine and its higher homologs, potent inhibitors of glutathione synthesis," The Journal of Biological Chemistry, vol. 257, no. 22, pp. 13704-13712, 1982. 
[64] G. Foure Seelig and A. Meister, "Glutathione biosynthesis; $\gamma$-Glutamylcysteine synthetase from rat kidney," Methods in Enzymology, vol. 113, pp. 379-390, 1985.

[65] S. A. Sheweita, N. Mousa, and H. M. Al-Masry, "N-nitrosodimethylamine changes the expression of glutathione S-transferase in the liver of male mice: the role of antioxidants," Journal of Biochemical and Molecular Toxicology, vol. 22, no. 6, pp. 389395, 2008.

[66] S. A. Sheweita and M. H. Mostafa, "N-nitrosamines and their effects on the level of glutathione, glutathione reductase and glutathione S-transferase activities in the liver of male mice," Cancer Letters, vol. 99, no. 1, pp. 29-34, 1996.

[67] N. A. Rigotti and C. Clair, "Clair Managing tobacco use: the neglected cardiovascular disease risk factor," European Heart Journal, vol. 34, no. 42, pp. 3259-3267, 2013. 


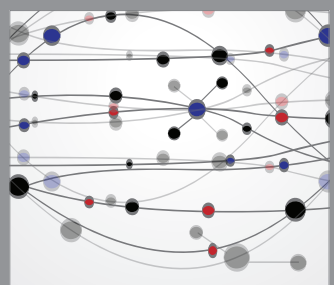

The Scientific World Journal
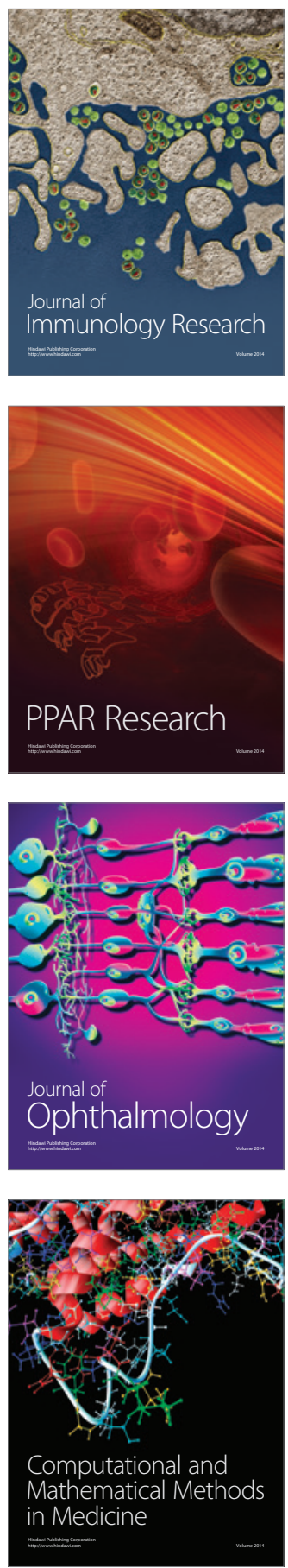

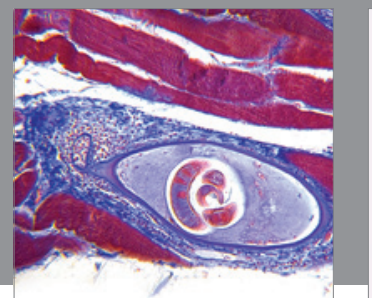

Gastroenterology

Research and Practice
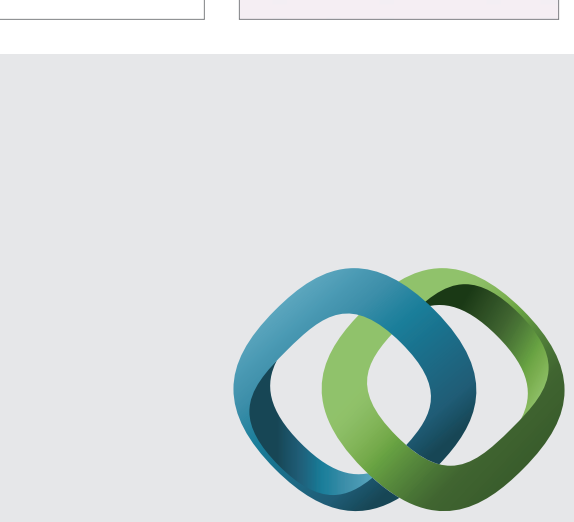

\section{Hindawi}

Submit your manuscripts at

http://www.hindawi.com
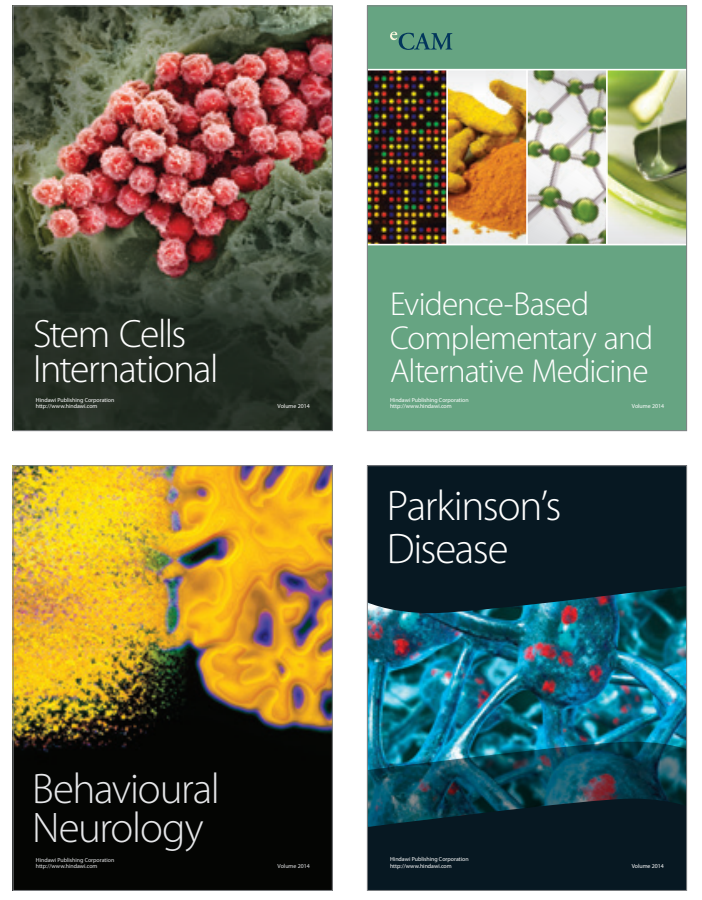
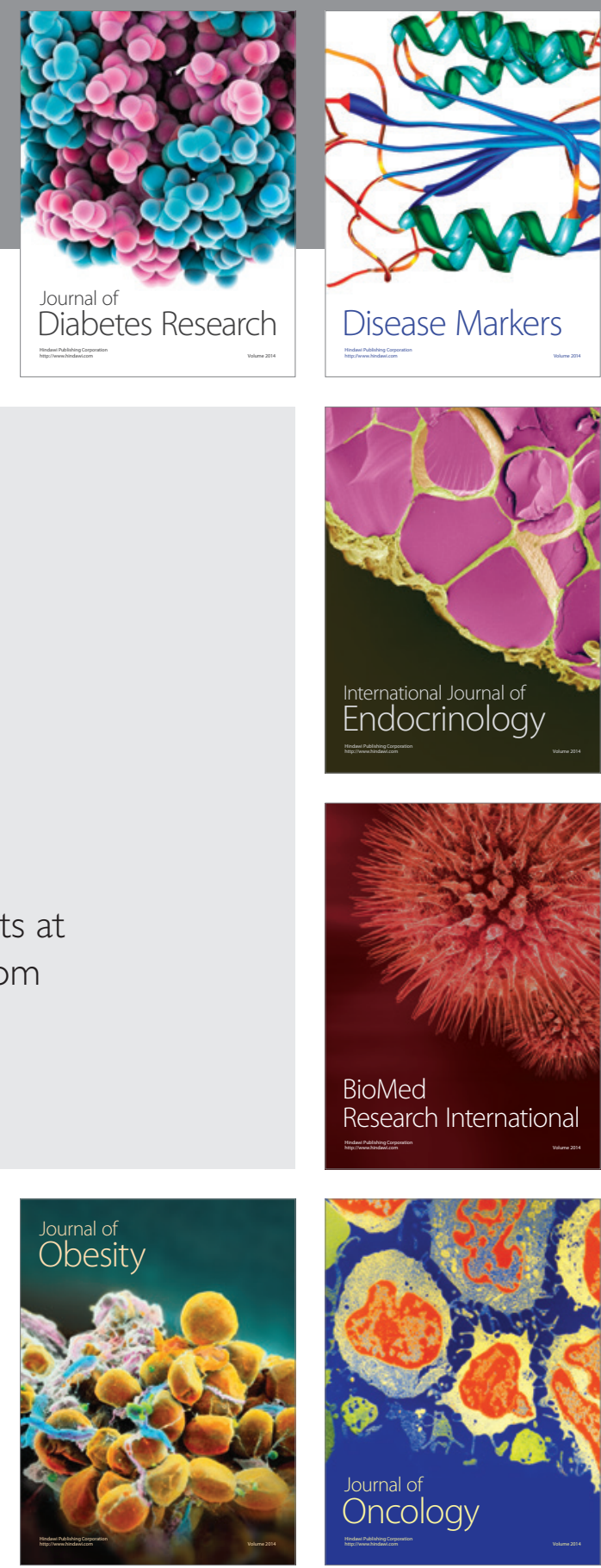

Disease Markers
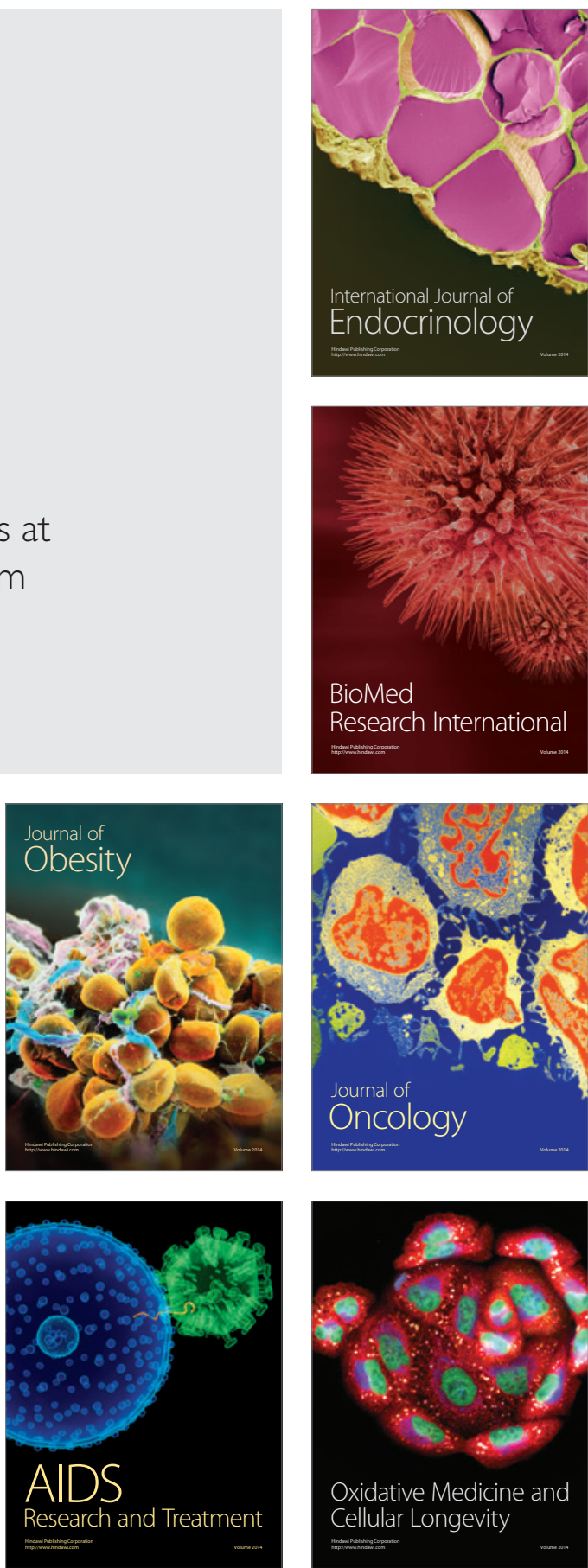